\title{
A ESCRAVIDÃO COMO MAL DE ARQUIVO: APAGAMENTO E ACONTECIMENTO NA HISTÓRIA DO BRASIL
}

SLAVERY AS ARCHIVE FEVER: ERASURE AND HAPPENING IN BRAZILIAN HISTORY

\section{Tânia Corghi Veríssimo \\ ORCID 0000-0002-9534-8696}

Universidade de São Paulo, São Paulo, SP, Brasil

\section{Resumo:}

O presente texto propóe discutir a complexidade do arquivo da escravidão no Brasil em suas dimensóes de apagamento e acontecimento na história do país. Para tanto, tomará como eixo o cotejo entre duas produçōes discursivas postas no laço social brasileiro, sendo estas o Hino da República de 1890 e o samba enredo produzido pela escola carnavalesca carioca Estaçáo Primeira de Mangueira no ano de 2019. Tomando como referencial teórico o mal de arquivo derridiano, pretende-se, ao longo do artigo, explorar as subversóes apresentadas por esta concepção de arquivo inovadora e fortemente marcada pelas noçôes freudianas de memória e pulsão de morte, bem como sustentar que a desconstrução do conceito de arquivo metafísico incide no campo político de modo a produzir consequências importantes no mesmo.

Palavras-chave: mal de arquivo, Derrida, psicanálise, escravidáo, memória.

\section{Abstract}

This text intents to discuss the complexity of Brazilian slavery archive in their dimensions of erasure and happening in the country's history. For this purpose, a comparison between two discursive productions placed in the Brazilian social context will be taken as the axis of this discussion: the 1890`s Brazilian Republic Anthem and the 2019`s samba song produced by the Carnival School Estação Primeira de Mangueira. Taking as a reference the Derridian notion of archive fever, the intention in this article is to explore the subversions presented by this innovative concept of archive which is strongly marked by the Freudian

\section{Résumé}

Le présent texte propose de discuter la complexité de l'archive de l'esclavage au Brésil dans ses dimensions d'effacement et d'évènement dans l'histoire du pays. Pour cela, a été pris comme axe la comparaison entre deux productions discursives mettant en évidence le lien social brésilien, à savoir l'hymne de la République de 1890 et la samba produite par l'école carnavalesque carioca "Estação Primeira de Mangueira " en 2019. Prenant comme référentiel théorique le mal d'archive derridien, l'intention tout au long de l'article est d'explorer les subversions présentées par cette conception d'archive innovatrice et fortement marquée par les 
notions of memory and death drive, as well as to posit that the deconstruction of the metaphysical concept of archive falls into the political field and has important consequences.

Keywords: archive fever, Derrida, psychoanalysis, slavery, memory. notions freudiennes de mémoire et de pulsion de mort, ainsi que de soutenir que la déconstruction du concept d'archive métaphysique retombe sur le champ politique de manière à produire d'importantes conséquences sur celui-ci.

Mots-clés: mal d'archive, Derrida, psychanalyse, esclavage, mémoire.

No ano de 1994, por ocasião de um colóquio internacional organizado por iniciativa de René Major e de Elizabeth Roudinesco ${ }^{1}$, em momento de efervescência política, Jacques Derrida realizou uma conferência intitulada "O conceito de arquivo. Uma impressão freudiana", na qual problematizou a concepção de arquivo que se fazia hegemônica nas ciências, pensando suas consequências. Passados sete anos, precisamente no ano de 2001, fez dessa conferência um ensaio, ao qual nomeou "Mal de Arquivo. Uma impressão freudiana", acentuando o mal como ingrediente fundamental e participante de qualquer arquivo da história.

Entende-se que tanto a focalização quanto a primazia oferecidas ao mal em seu ensaio se deram de maneira não aleatória. Ainda que, num primeiro momento, a adição da conjunção "de" entre as corriqueiras palavras "mal" e "arquivo" possa soar despretensiosa, tal alteração semântica deverá ser tomada, sobretudo, como confrontação à naturalização e alavanca ao inédito. Ao fundar o sintagma "mal de arquivo", Derrida plantou o enigma, forjou algo que não permite compreensão óbvia e/ou significação imediata, repondo a não clareza, a evanescência e a não univocidade do termo para quem o acessa ou o escuta. Rebento da desconstrução, ou seja, de uma estratégia de leitura crítica que, fundamentalmente, consiste no questionamento da atmosfera de obviedade circundante à ideia tradicional posta em diferentes e quaisquer teorias, incluindo a do arquivo metafísico, o "mal de arquivo", pode-se dizer, abre em sua potência novos caminhos à reflexão a respeito das particularidades contidas nos modos como concebemos e arquivamos episódios históricos.

Tal constatação permite aportar que, desde o Mal de Arquivo (2001), não haverá mais espaço para a sustentação do arquivo do senso comum, este que seria estático e fixo na sua consistência ontológica, concernente a um "conjunto de documentos estabelecidos como positividades, na sua materialidade, e que seria ainda, na sua pretensa objetividade, o reflexo do que ocorreu de fato na experiência histórica” (BIRMAN, 2008, p. 109),

$1 \mathrm{O}$ colóquio internacional levou o título: "Memória: a questão dos arquivos" e se realizou em Londres sob auspícios da Sociedade Internacional de História da Psiquiatria e da Psicanálise, do Museu Freud e do Instituto de Arte Courtauld. 
para o tal arquivo historiográfico hegemônico, pretensamente homogêneo, isento de lacunas e furos, depositado e relegado aos recônditos de alguma gaveta, por fim arquivado no sentido do encerrado. Ao contrário, em sua abertura para o novo, temos através desta obra a subversão da soberania do arquivo tradicionalmente posto, o firmar de uma concepção outra de arquivo que traz em seu cerne a propriedade de portar desde sempre uma disjunção, uma ambiguidade e uma dualidade fundamental, sendo um de seus efeitos a configuraçáo de outra relaçáo do sujeito com o seu tempo.

Pelo advento do mal de arquivo, temos as indagaçóes acerca do arquivar, registrar, transmitir estabelecidos pelo senso comum. Desde esta noção, os marcadores dicotômicos "antes e depois, dentro e fora, aberto e fechado, aparecer e desaparecer, lembrar e esquecer, sim e não" foram relativizados pela insurgência de uma nova representação, mal de arquivo, que concatena o irrepresentável inerente a qualquer produção simbólica. Aberto horizonte de reflexão sobre nova compreensão de arquivo, agora constituído e trabalhado pelo mal em seu cerne, pensemos desde então na lógica que náo obedece à cronologia linear do passo a passo, e sim no passado que não passa, na lembrança que não se rememora, no esquecimento que faz memória, na negativa eloquente.

Embaralhados binarismos reducionistas, há que se localizar a insurgência do termo "mal de arquivo" sem cometer o deslize de desassociá-la da filosofia e da marcante personalidade de Jacques Derrida. Suas produçóes o apresentam: sujeito migrante, atento às fronteiras e à estrangeiridade, amante e estudioso da língua e da letra, militante, expatriado, pied-noir, insurgente, tal qual seu "mal de arquivo". A insurgência, portanto, marca impressa em sua trajetória, virá congruente à desconstrução, esta estratégia crítica que elegeu as palavras como vias privilegiadas para fazer valer seu propósito político na direçáo da transformação. Reconhecidamente "o intelectual da discordância" (FREIRE, 1995/2018), aquele que "como todo grande intelectual, não entregaria fácil seu saber" (MATOS, 2018), Derrida propôs criticar e desconstruir, tomando a filosofia como "pensar em ação", ou seja, como um modo de intervir no mundo jamais alijado do engajamento necessário².

Importante considerar que, para a discussão sobre o arquivo, para a efetivação de um propósito de libertação dos laços até então considerados naturais, Derrida não apenas convidou a psicanálise freudiana para esta

2 Derrida jamais divorciou seus escritos de seu engajamento político. Observa-se em sua trajetória a militância contra a pena de morte, sua defesa aos sem-documentos, sua adesão à causa das minorias como mulheres, homossexuais, e sua luta contra o apartheid. A partir de 1994, ano em que Nelson Mandela instituiu a Comissão Nacional da Verdade e Reconciliação, que pretendia alcançar a "verdade" como condição para o perdão, o filósofo acompanhou de perto o funcionamento da comissão sul-africana, parecendo particularmente interessado no mecanismo de vir à tona, identificando aí um movimento oposto ao do recalque que tudo esconde e oprime (RODRIGUES, 2006, p. 331). 
interlocução como a apontou como presença indispensável de potencial revolucionário para tal alcance.

Pode-se observar no "Mal de Arquivo" (2001) sua busca por noções e diretrizes trazidas por Freud para fundamentar seu horizonte de problematização ética acerca do que se revelou para ele um disparador da discussão entoada em seu ensaio: os chamados arquivos do mal, ou seja, aqueles documentos "dissimulados ou destruídos, interditados, desviados, recalcados" (DERRIDA, 2001, p. 7). Para ele, "Os desastres que marcam o fim do milênio são também arquivos do mal (...) Seu tratamento é ao mesmo tempo massivo e refinado ao longo de guerras civis ou internacionais, de manipulaçôes privadas ou secretas" (DERRIDA, 2001, p. 7). Com o olhar voltado ao secreto, ao que tende ao escondido e/ou recalcado, ao silenciado pelo excesso trazido pela experiência traumática, propôs: "Pensemos nos debates sobre todos os revisionismos, pensemos nos sismos da historiografia, nas reviravoltas técnicas do estabelecimento e do tratamento de tantos "dossiês" (DERRIDA, 2001, p. 7).

A psicanálise, ao apresentar uma concepção inovadora de memória, permitiu a compreensão de que marcas históricas tanto podem se mostrar fortes e resistentes ao tempo quanto silenciadas e combatidas no ato da inscrição psíquica, no exercício constante do fazer memória. Obediente à lógica inconsciente, esta que subverteu a equação memória-recordação, temos uma memória então reveladora de sua potência de construção de traços ao mesmo tempo em que passível de apagamento num cenário dual e conflitivo, fazendo indagar sobre o que consiste, em psicanálise, fazer e desfazer memória. "Por que lembramos mais do que esquecemos do que daquilo que conseguimos lembrar? Em psicanálise, não lembrar pode ser justamente a prova de que algo ficou registrado" (GUELLER, 2005, p. 53).

Sabe-se que Derrida estabeleceu seu percurso de estudo acerca da concepção de memória freudiana anteriormente ao Mal de Arquivo (2001). Assim, temos pela "Carta 52" (1896/1996) que a memória se constitui na tessitura de traços sobre o aparelho psíquico, estabelecendo um embriáo do arquivo, uma vez que vinculou a lógica da escritura ao psiquismo, pensando-o em termos de estratos psíquicos e texto dotado de signos de percepção passíveis de tradução. Em seguida, o artigo "Notas sobre o bloco mágico" (1925/2010) fez-se grande divisor de águas no estabelecimento do "bloco": uma metáfora arquival que efetivamente conferiu ao psiquismo uma qualidade hipomnésica, sistematizando a exterioridade capital à constituiçáo do arquivo, tal como estabeleceu Derrida (2001).

A cara noção psicanalítica de inscrição psíquica fora ilustrada no "Mal de Arquivo" (2001) através da imagem do exergo, originária do grego ex "fora" e érgon "obra", "trabalho", definida também como "espaço de uma moeda 
ou medalha em que se grava uma inscrição ou data" ${ }^{3}$, calcada na ideia de inscrição sobre um objeto. Derrida utiliza o exergo como exemplo fundante para pensar a força de impressão de algo sobre uma estrutura, além dos aspectos contraditórios portados por um arquivo constituído, inescapavelmente, por duas ordens de forças concorrentes: a institutriz e a conservadora a um só tempo. Aproxima-se da questão da força, do poder, da violência da instituição. Nas palavras de Derrida (2001):

Segundo uma convenção sagrada, o exergo se articula com a citação. Citar antes de começar é dar o tom deixando ressoar algumas palavras cujo sentido ou forma deveria dominar a cena. Dito de outra maneira, o exergo consiste em capitalizar uma elipse. Acumular de antemáo um capital e preparar a mais-valia de um arquivo. Um exergo estoca por antecipaçáo e pré-arquiva um léxico que, a partir daí, deverá fazer a lei e dar a ordem contentando-se em nomear o problema, isto é, o tema. Há uma funçáo a um só tempo institutriz e conservadora no exergo: violência de um poder (Gewalt) que ao mesmo tempo coloca e conserva o direito (...). ( p. 17).

Depois, na mesma medida em que a confecção de traços de memória/ inscrição psíquica surge no "Mal de Arquivo" (2001) ilustrada pela imagem do exergo, pela marca cravada sobre um objeto portador de uma eterna gravaçáo, modificado inescapavelmente pela força e pela violência de um ato inscrito agora irrevogável, vale retomar que, para compreender o arquivo derridiano, faz-se necessário recuperá-lo enquanto registro formado pelo mal, enquanto morada de paradoxos, a um só tempo instituidor e conservador, revolucionário e tradicional, "ofertado e furtado à tradução, aberto e subtraído à iteração e à reprodutibilidade técnica" (DERRIDA, 2001, p. 118) que trará em seu cerne grande força de acontecimento e apagamento.

É válido destacar que tal arquivo, ao mesmo tempo em que formado de traços, na medida em que marcado pelo excesso, apresentar-se-á em sua condiçấo devoradora de traços, terá característica anarquívica e arquiviolítica e convidará a pensar em um potencial de extermínio e destruição instalado no coração do arquivo com raios de alcance até entáo incalculáveis. Tal arquivo, conforme já mencionado, não se localizará mais em territórios ingênuos nem estará restrito a uma zona de clareza e definição. Ao contrário, deitará em um campo de brigas entre forças pulsionais contrárias, anunciando o indecidível interstício entre a constituição de laços e memória, e a tendência ao desfalecimento e à aboliçáo simbólica inerente aos arquivos da cultura.

Partindo do contraponto na constituição da memória psíquica, tomada pela tendência destruidora de arquivos na discussão sobre a fabricação dos

3 Dicionário Online da Língua Portuguesa (https://www.dicio.com.br/exergo/). 
arquivos do mal, nota-se a ousadia de Derrida, que não apenas acolheu a pulsão de morte em sua obra, mas elaborou sua própria definição de tal pulsão, desembocando em sua renomeaçáo: pulsão arquiviolítica. Passado quase um século da criação da noção de pulsão de morte e pulsão de destruição na obra freudiana (1920-1930), temos Derrida com novas palavras, rebatizando e/ ou redimensionando um conceito da envergadura da pulsão de morte para a psicanálise.

A noção de pulsão arquiviolítica merece destaque em sua definição:

Mais tarde, Freud dirá que esta pulsão com três nomes é muda (stumm). Ela trabalha, mas uma vez que trabalha sempre em silêncio, não deixa nunca nenhum arquivo que lhe seja próprio. Ela destrói seu próprio arquivo antecipadamente, como se ali estivesse, na verdade, a motivação mesma de seu movimento mais característico. Ela trabalha para destruir o arquivo: com a condiçâao de apagar mas também com vistas a apagar seus "próprios" traços - que náo podem desde entáo serem chamados "próprios". Ela devora seu arquivo, antes mesmo de tê-lo produzido externamente. Esta pulsão, portanto, parece náo apenas anárquica, anarcôntica (...) a pulsão de morte é, acima de tudo, anarquivica, poderíamos dizer, arquiviolítica. Sempre foi, por vocação, silenciosa, destruidora do arquivo. (DERRIDA, 2001, p. 21).

Observa-se o protagonismo da pulsão arquiviolítica no "Mal de Arquivo" (2001). Sua centralidade na obra faz pensar sobre a possibilidade do alcance de novas palavras, novo enfoque e entonação para tratar dos efeitos da pulsão de morte e dos traumas e catástrofes que assolam a humanidade. Como lidar com esta chamada pulsão arquiviolítica? Uma vez que a reflexão sobre os arquivos do mal apresenta a pulsão de morte/arquiviolítica não apenas como força que atravessa o arquivo, mas sim trabalha contra ele mesmo em sua constituição, como compreendê-la em seus raios de ação? Como entender a presença da pulsão arquiviolítica na política de constituição do arquivo que, conforme já pontuado, traz em si mesma uma potência de acontecimento e apagamento?

Tais indagações alçam dois pontos que se articularão neste artigo a propósito da abordagem do mal de arquivo enquanto proponente de uma questão ético-política localizada na esteira do traumático da história. $\mathrm{O}$ primeiro ponto refere-se à subversáo da lógica cronológica temporal posta pelo arquivo derridiano, este arquivo subversivo à ideia do arquivo reservado ao passado, datado e circunscrito a um tempo que passou, aberto agora para aquilo que surge deslocado no tempo, revoltado, impertinente e atávico. $\mathrm{O}$ segundo ponto, por sua vez, trata da propriedade anarquívica e arquiviolítica inerente ao arquivo, desembocando numa concepçáo de arquivo pautada pela pulsão de morte enquanto presença decisiva. 
Ambos pontos se articulam nesta discussão. Ora, podemos pensar que eventos de magnitudes pulsionais intensas e extremas engendrados pela força arquiviolítica dos arquivos da história embaralham o campo temporal, constituindo os chamados arquivos do mal. A lida com a prevalência da pulsão de morte, ou seja, com uma força de trabalho excessiva que depóe contra o trabalho psíquico, impóe uma reflexáo sobre o tempo, tendo em vista que esta pulsão arquiviolítica, impeditiva de qualquer inscrição e transcrição no exercício do fazer memória, corrobora o trauma em seu caráter sempre atual de apresentação contraposto à representação; de apresentação de feridas seculares surgidas em tinta fresca dada a impossibilidade de se representar.

Compreendido que, aqui, a memória não se refere à anamnese ou à ressurreição dos fatos objetivos, e sim à memória da psicanálise, modelo para Derrida subverter a noção de arquivo, mergulharemos na lógica não linear de problemáticas ligadas ao traumático da história que se apresentam de modo disruptivo com ares de atualidade. Afinal, tais arquivos não obedecem à cronologia, não parecem se desgastar com o tempo, não seguem o suposto "começo, meio e fim", são alvos de destruição, silêncio e manipulação, compóem obscuros dossiês e trazem à tona a força da pulsão arquiviolítica: são os chamados arquivos do mal.

Tomaremos como exemplo de arquivo do mal a produção dos paradoxos existentes no Brasil a respeito de sua história escravocrata. Com base na subversão trazida pelo arquivo derridiano, pelo mal de arquivo, pensaremos sobre a relaçáo do brasileiro com o arquivo escravidão, este registro fundante e estrutural, cravado nos primórdios de nossa história. Como nós, brasileiros, arquivamos a escravidáo enquanto realidade que oficialmente atravessou/ atravessa nosso país por mais de três séculos? Como pensar este arquivo escravidáo desde a perspectiva do apagamento e acontecimento na história brasileira portadora do traumático em seu seio?

\section{Arquivo e apagamento}

Localizo em trabalho anterior a abordagem do tema do racismo como problemática brasileira no qual se sustenta a hipótese da existência da recusa como mecanismo de defesa psíquico posto no laço social brasileiro (AUTOR, 2015). Na ocasiáo, elegeu-se como disparador para a escrita um trecho do Hino da Proclamação da República escrito no ano de 1890, dois anos após a dita abolição da escravidão.

Destaco o trecho:

Liberdade, liberdade, abre as asas sobre nós, das lutas na tempestade, dá que ouçamos tua voz, nós nem cremos que escravos outrora tenha havido em táo nobre país. Hoje o rubro lampejo da aurora acha irmãos, não tiramos hostis. (MEDEIROS; ALBUQUERQUE, 1867-1934). 
A frase "nós nem cremos que escravos outrora tenha havido em tão nobre país” produziu inquietação. Intrigante foi pensar que um acontecimento tão incontestável e escandaloso como a escravidão, tão estruturante da subjetividade do povo brasileiro, dois anos após a "abolição", havia sido tão rapidamente incluído em um hino ocupado em bradar a crença na não existência de tal acontecimento. Curioso foi também constatar neste hino a evocaçáo direta do apagamento da experiência de um fato tão terrorífico e consumado enquanto via de extermínio e desumanização de tantos sujeitos.

Diante da pauta do racismo recusado, legado do trauma da escravidáo no Brasil, foi possível pensar, através desta discussão, na sustentação da crença na nobreza de um país sem passado, na crença no silêncio como meio de lidar com a violência, crença em uma história fetiche que impóe o desmentido da realidade, instalando a tal versão oficial, folclórica, mítica. Também foi possível refletir sobre o brasileiro que, como disse Mannoni (1973), "sabe, mas mesmo assim”, admitindo a existência e recusando sua percepção da realidade às custas da cisão do Eu.

Mannoni (1973) descreveu o mecanismo da recusa/ Verleugnung assinalando sua atuação direta no Eu através da cisão. Partindo do estudo freudiano Sobre o Fetichismo (1927), quando Freud tomará a experiência de descoberta da realidade da castração materna como traumatizante, o psicanalista pensará sobre a divisão que, desde entấo, vem assolar o psiquismo. Daí ocorre uma coexistência de partes do Eu que coabitam sem comunicação: a crença na existência do falo é atacada pelo desmentido da realidade, mas, ao mesmo tempo que tal crença é confrontada e admitida parcialmente, é preciso que esta sobreviva, e seja, por outro lado, conservada a despeito de qualquer testemunho da realidade.

Eu sabia (evidentemente) diz que, sendo a tempestade bastante natural, não teria o menor motivo de me surpreender. Mas apesar disso, (mas mesmo assim) um começo de medo me fazia desejar estar no quarto. Vemos assim a última defesa antes do pânico, a mais vã, a do bom senso. E estamos em condição de explicar sua inutilidade: é que o bom senso está sempre do lado do "eu sei" nunca do "mesmo assim". O "eu sei" é levado como uma palhinha num pânico total, a magia se vinga: no terror que me abateu, persuadi-me de que, se os raios que eu via não vinham me destruir, eram porque não podiam entrar no círculo. Sem essa falsa crença não teria ficado lá nem um minuto. Assim, o círculo era mágico - mesmo assim. (MANNONI, 1973, p. 28).

Nem cremos que escravos tenha havido em táo nobre país?

Alinhada à reflexão de Mannoni (1987) a respeito da recusa como mecanismo de defesa psíquico frente a um evento traumático, encontramos a narrativa de Zaltzman (2018), corroborando a cisão posta no laço social quando acometido pela barbárie: 
Estranho que todos os crimes contra a humanidade se deparam com o mesmo registro de defesa, com esta mesma clivagem entre uma responsabilidade coletiva anônima que não recairia sobre ninguém e uma ausência de responsabilidade individual através da invocação de superiores hierárquicos, da obediência às ordens, da pressão sofrida, da ausência de escolha e da ignorância: não se sabia, náo se queria (p. 15).

Agora, com Derrida, é possível trazer novas palavras para iluminar a questão na medida em que ele, no Mal de arquivo (2001), enuncia e sustenta a necessidade de levarmos a sério a disjunção estrutural que marca os arquivos da história, aponta para a força de apagamento inerente, para a pulsão de morte no coração do arquivo, para o arquivo como sítio paradoxal entre o desejo de acontecer, a morte e a destruição antes de adquirir a possibilidade de tornar-se próprio. Eis esta relação posta no arquivo da escravidão brasileira, este que se tornou um arquivo do mal, imerso em desvios e recusas para a sustentação de uma versão soberana e silenciadora daquilo que existe de mais sangrento.

Para pensar sobre esta sustentação de uma versão mítica e silenciadora do trauma da escravidão que marca a fundação do Brasil, retomo a afirmação de Derrida (2001) a respeito da pulsão arquiviolítica enquanto algo que "não deixa como herança senão seu simulacro erótico, seu pseudônimo em pintura, seus ídolos sexuais, suas máscaras de sedução: belas impressóes” (p. 22). Trata-se da ação da pulsão de morte que, quando não trabalha para a destruição do arquivo, trabalhará para "disfarçá-lo, maquiá-lo, pintá-lo, imprimi-lo, representá-lo no ídolo de sua verdade em pintura" (DERRIDA, 2001, p. 23), ameaçando todo o desejo de arquivo em vocação silenciosa de queimar o arquivo e levar à amnésia.

Relembremos também do arquivo derridiano que, em sua realização político-institucional, será retirado de uma zona de clareza e univocidade. Duque-Estrada (2010) compreende que a concepção derridiana do arquivo abre para uma nova forma de pensar o âmbito da política, articulando três dimensóes responsáveis por esta nova configuração e que se encontram interligadas no Mal de Arquivo (2001): primeiramente, a amplitude ilimitada da dimensão política do arquivo que contempla momentos como o da seleção, passando pela conservaçáo e pelo acesso, chegando à leitura dos documentos; depois, a sua relação com a questão da democracia, na referência de que a democratização efetiva se mede sempre pelo critério essencial de participação e o acesso ao arquivo, à sua constituição e à sua interpretação; e, finalmente, o seu interesse pela psicanálise, na consideração da participação do inconsciente na constituição do arquivo.

Frente a essas questóes, constitui-se o chão para perguntas sobre quem acessa o arquivo, quais as condições de sua configuração. Mas a quem cabe, em última instância, a autoridade sobre a instituição do arquivo? 
Nas reflexóes sobre o como arquivar, importante trazer Derrida (2001) quando diz que "não se vive mais da mesma maneira aquilo que não se arquiva da mesma maneira" (p. 31), apontando que o sentido arquivável se deixa também e de antemáo codeterminar pela estrutura arquivante, que o arquivamento tanto registra quanto produz o arquivo e que a estrutura técnica do arquivo arquivante será determinante na constituiçáo do conteúdo de certo arquivo.

Como arquivamos e como arquivaremos? Como nos encarregaremos de registrar episódios traumáticos de nossa história? A compreensão de que a vivência e relaçáo com determinado episódio serão moldadas pelo modo de arquivar tal episódio oferece a possibilidade de prospectar novos modos de arquivamento, logo novas vivências, novas produçóes, portanto.

Ao pensar na escravidão como arquivo do mal, semblante pintado como assunto inexistente num hino feito dois anos depois da dita abolição, assunto alvo de negacionismos e recusas que cindem seu aspecto mais violento, e como arquivo tomado de uma versão da história pautada pelo chamado mito da democracia racial e pelas leituras mais cínicas empenhadas em obscurecer injustiças, há que se atentar para os desdobramentos dessas maneiras nefastas de arquivar a história. Ora, se para Derrida não viveremos mais da mesma maneira aquilo que não arquivaremos da mesma maneira, então tomemos a posiçâo de analisar criticamente o que significam os arquivos alarmantes e genocidas ligados à população negra brasileira cotidianamente. A que o genocídio negro nos convida a pensar a respeito do nosso modo de arquivar? Como arquivamos e como arquivaremos? Qual será nosso posicionamento frente a este arquivo da história?

Este arquivo que, conforme já enfatizado, não representa mero estoque do passado, mas uma dimensão viva e pulsante, aberta ao futuro. Arquivo que abriga o traumático em seu cerne, embaralhando a cronologia e trazendo a perturbação como força de acontecimento atual. Relembro Derrida (2001) quando diz que "Nada é menos claro, nada é menos garantido hoje em dia do que a palavra arquivo (...) nada é tanta perturbação nem mais perturbador" (p. 117). Arquivo que é perturbador na medida em que coloca em cena o mal, expóe a dualidade estrutural e aquilo que há de mais traumático na história, não representado e potencialmente desorganizador do status quo.

Com Benjamin, temos a importante afirmação de que nunca houve um monumento da cultura que não fosse também um monumento da barbárie (BENJAMIN, 2012). Com Freud, a lembrança de que não há civilização sem mal-estar (FREUD, 1930/2015). Com Derrida, nesta mesma linha, a sustentação que não haverá arquivo sem mal de arquivo (DERRIDA, 2001). 
$\mathrm{O}$ arquivo, desde entáo, encontra-se referido a um campo de contradições inerente à sua constituição e nos ensina que o debruçar sobre a complexidade de catástrofes seculares tais como a Shoah, as guerras colonialistas, os genocídios impiedosos e a política da escravidão perpetrada no Brasil por séculos a fio implica na necessidade da sustentação de um tensionamento intrínseco a este arquivo. Este arquivo que, uma vez situado na dobradiça do escândalo desumanizante com a naturalização ceifadora de qualquer espanto e reconhecimento da violência, será também porta-voz de uma espécie de "tudo ou nada" entoará um canto potente na briga de forças entre a real existência e seu real apagamento e a invalidação na cultura pelo excesso traumático.

Nesse sentido, localizar-se na dobradiça para ler o andar da história, admitir movimentos que envolvem oscilações entre o "sim e não" de episódios traumáticos postos na vida cultural, reconhecer as lutas concomitantes por "acontecimento e apagamento" de eventos incontestes e de grandes magnitudes pulsionais são posiçóes fundamentais para quem pretende, portanto, avançar em um propósito transformador de encontro à verdade e à responsabilidade ética. O Mal de Arquivo (2001) póe e repóe tal dobradiça, e olha tanto para a contradição de uma história que sofre ao mesmo tempo de um mal de apagamento e acontecimento quanto para a concomitância vida e morte a qual aporta a pulsão arquiviolítica.

De fato, a pulsão arquiviolítica não deve ser lida apenas em seu potencial de destruição. Tal pulsão aporta uma concomitância nevrálgica. E Derrida (2001), ainda que atento aos raios de ação de uma pulsão arquiviolítica em sua face arrasadora, mira para sua dualidade em ambas as direçóes - vida e morte - quando atenta tanto para uma pulsão destruidora, sem a qual não haveria, com efeito, para o arquivo, nenhum desejo ou possibilidade de sobrevivência e/ou permanência, quanto para a existência de razóes estratégicas que implicam todas as tensôes, contradições ou aporias nas condições de arquivamento ao esboçar a promessa, o futuro e um porvir. Segundo o filósofo: "Por um lado, o arquivo é possibilitado pela pulsão de morte, de agressão e de destruição, isto é, também pela finitude e pela expropriação originárias" (DERRIDA, 2001a, p. 121).

Assim, o mal de arquivo que a um só tempo apaga e constitui traz para o centro do debate este apagamento e esquecimento de traços de memória como condição de possibilidade para sua própria renovação e acontecimento. Tal interdependência, com efeito, não poderia deixar de apresentar a pulsão arquiviolítica em sua potência destruidora do desejo de memória, bem como 
possibilitadora de tal desejo; como força que advém tâo problemática, na medida em que é capaz de instalar um problema ético-político, quanto necessária para que um arquivo então se constitua.

Nas palavras de Derrida (2001):

Náo haveria certamente desejo de arquivo sem a finitude radical, sem a possibilidade de um esquecimento que não se limita ao recalcamento. Sobretudo, e eis aqui o mais grave, além ou aquém deste simples limite a que chamam finitude, não haveria mal de arquivo sem a ameaça desta pulsão de morte, de agressão ou de destruição. Ora, esta ameaça é in-finita: ela varre a lógica da finitude e os simples limites factuais, a estética transcendental, ou seja, as condiçôes espaço-temporais da conservação. Digamos melhor: ela abusa. (...) (DERRIDA, 2001a, p. 32).

Isso posto, podemos pensar que o trabalho com a pulsão arquiviolítica não apenas como aquilo que exterminaria a memória, mas como força necessária à formaçáo do arquivo, figurará o mal de arquivo de modo mais auspicioso do que foi pensado até então. Temos agora a ênfase ao arquivo não apenas em sua faceta de apagamento, mas de acontecimento.

Apoiados em duas afirmaçóes de Derrida, encontramos no Mal de Arquivo (2001) este anúncio auspicioso. Na primeira afirmação, depois de pensado incongruente à mera estocagem do passado, o arquivo surge situado como aquele que "deveria pôr em questão a chegada do futuro" (DERRIDA, 2001, p. 48). Na segunda, localiza-se um importante contraponto a tamanho cenário de destrutividade trazido pela pulsão arquiviolítica no momento em que Derrida (2001) traz o inconsciente enquanto força inarredável na constituição do arquivo: "Não se renuncia jamais, é o próprio inconsciente, a se apropriar de um poder sobre o documento, sobre sua detenção, retenção ou interpretação" (p. 07).

Poderíamos pensar que esta não renúncia ao próprio inconsciente operaria frente às forças de extermínio mais radicais? Podemos apostar na potência do inconsciente como constitutivo da realidade e produtor incessante de restos e rastros contra um mal de apagamento? Estaríamos diante da reflexão de ZALTZMAN (2018) a respeito do que nomeou "identificaçâo sobrevivente", ou seja, do "resto impossível de ser apagado numa política tanática, seja esta qual for" (p.19/20)? Podemos então nos localizar no campo do "traço inconsciente que resistirá ao universo concentracionário da vida matável, um traço que faz fracassar a destruição"? (ZALTZMAN, 2018, p. 19/20).

A escravidão é um arquivo do mal que escancara o mal de arquivo enquanto questão. Foi abolida oficialmente no século XIX, mas até hoje carrega as tentativas de recusa de sua real existência na história do país. Passados quase dois séculos de sua abolição, o ano de 2019 ainda expóe a dualidade 
fundamental inerente a este arquivo. Há quem diga que a escravidáo nunca existiu, que o racismo, legado do trauma da escravidão, não existe ${ }^{4}$.

No entanto, se falar sobre o arquivo é falar sobre a sustentação de contrários, é tratar do contrapelo e do mal; se arquivo é, ao mesmo tempo, apagamento e acontecimento, embora ainda encontremos diversas corroborações do "nem cremos que escravos tenha havido em tão nobre país" posto no Hino da República (1890) e em tantos outros espaços políticos e sociais enquanto força mortífera de apagamento, pode-se dizer que, no ano de 2019, o país apresentou seu contraponto, sendo agraciado com um novo hino.

Tomando a definiçẫo de hino nacional, quando ligado a uma pátria, como algo que configura "geralmente uma composição musical patriótica que evoca e elogia a história, as tradiçóes e as lutas de seu povo, reconhecidas pelo governo de um país como a canção nacional oficial símbolo do Estado, ou por convenção, através do uso pelo povo"s, tivemos no ano de 2019, na festa mais tradicional do país, o carnaval, mais do que a apresentação do sambaenredo da escola de samba carioca campeã Estaçáo Primeira de Mangueira, mas, de certo modo, a fundaçáo de um novo hino brasileiro.

Cito um trecho:

Brasil, meu nego deixa eu te contar. A história que a história não conta. $\mathrm{O}$ avesso do mesmo lugar (...) Brasil, meu dengo, a Mangueira chegou. Com versos que o livro apagou. Desde 1500 tem mais invasão do que descobrimento. Tem sangue retinto pisado. Atrás do herói emoldurado. Mulheres, tamoios, mulatos. Eu quero um país que não está no retrato.

O samba enredo, hino da escola de samba Estaçáo Primeira de Mangueira vem reafirmar a dimensão viva e pulsante do arquivo tão enfatizada por Derrida (2001). Esta que não se contentou com a versão de arquivo da história como passado empoeirado nos poróes e não só deveria pôr como pôs em questão a chegada do futuro. Esta que demonstra a dimensão de todo arquivo lacunar e sintomático e reveladora da força do inconsciente na produção de traços que tanto a pulsão arquiviolítica tenta extinguir quanto produzir. Esta que, não submetida ao tempo linear e cronológico do passar dos anos, surge impactante e que, com o enredo denominado "História pra

4 Atenção à força com que surge tal discurso de apagamento cravado no arquivo brasileiro sobre a escravidão. Consideremos que no Brasil, o atual presidente da república Jair Messias Bolsonaro, eleito recente e democraticamente no ano de 2018, em entrevista concedida em canal aberto da mídia televisiva, o então na época deputado e presidenciável, enunciou sua interpretação sobre o dado historicamente comprovado de mais de três séculos de escravidão no país: "Se for ver a história realmente, os portugueses nem pisavam na África, eram os próprios negros que entregavam os escravos" (https://exame.abril.com. br/brasil/no-roda-viva-bolsonaro-questiona-escravidao-e-cotas/).

5 <https://pt.wikipedia.org/wiki/Hino_nacional>. Acessado em 08/03/2020. 
ninar gente grande" mais acreditar em história pra boi dormir.

Agora cravado na história do Brasil, temos um novo hino, ou seja, novo discurso, marca constituída, arquivo que alça a discussão sobre a opressão e violência perpetuadas em nosso país a outro patamar de conversa. Como disse Endo (2019): "Não há maneira de falar mais alto do que consagrando às festas a sua potência política" ( $\mathrm{s} / \mathrm{p})$. Tivemos retrocessos políticos desanimadores em nosso país, mas tais retrocessos também se deram "No ano em que nossa maior festa foi séria, repleta de esperanças, imaginação e inspiradora de caminhos a seguir, lutando, dançando, cantando e mais cientes do Brasil que precisaremos defender" (ENDO, 2019, s/p).

Seria coincidência um samba-enredo portador do contrapelo da história oficial do Brasil, revelador da voz das minorias, dos oprimidos e alvos de extermínio, ter atingido tanta glória e repercussão popular justamente em um ano marcado pela inauguração de uma política nacional declaradamente obscurantista?

Aqui podemos trazer as palavras de Seligmann-Silva (2018) ao partir da arte como campo "anarquivador", da figura do artista como alguém que vem "embaralhar os arquivos, pôr em questão as fronteiras, tentar abalar poderes, revelar segredos, reverter dicotomias para entáo as explodir" (p.62).

Desse modo, temos o artista e a arte em seu lugar subversivo que traz à tona aquilo que se tornou alvo de obscurantismos, aquilo que foi negado, banido, retirado de circulaçáo e extirpado do escopo de um discurso oficial:

A palavra de ordem é anarquivar para recolecionar as ruínas dos arquivos e reconstruí-las de forma crítica. A artista se assume como demiurgo e não mais como participante submisso, como queriam os fascismos e totalitarismos do século XX, que tentaram submeter as artes e os projetos megalomaníacos de arquivamento da sociedade e de seus indivíduos (SELIGMANN-SILVA, 2018, p. 62).

Lembrando que Derrida (2001) compreende esta relação com os arquivos do mal, ou seja, com o retorno do recalcado da história ou com os pedaços do material psiquicamente recusado por anos a fio, como algo que evoca sem dúvida um sintoma, um sofrimento, uma paixão. Paixão e carnaval! Desde então, podemos entender que o mal surge vinculado à paixão, à impaciência, a uma experiência pulsional em sua dualidade radical, que se dará no coração do arquivo. $\mathrm{O}$ mal de arquivo que, no idioma francês, adquire o sentido de um "arder de paixão" em busca de memória:

6 Composição: Tomaz Miranda, Ronie Oliveira, Márcio Bola, Mamá, Deivid Domênico, Danilo Firmino. 
Frente àquilo que arruína, desvia ou destrói o próprio princípio do arquivo levanta-se então infinita, fora de proporção, sempre em curso, "em Mal de Arquivo", a espera sem horizonte acessível, a impaciência absoluta de um desejo de memória. (DERRIDA, 2001, p. 10).

Memória que, assim como o arquivo, opera fundamentalmente por contradições, pela sustentação de contrários e torna enganado aquele que tomar o arquivo como lócus da memória sem olhá-lo como lugar do próprio desfalecimento.

Pois o arquivo, se esta palavra ou esta figura se estabiliza em alguma significaçáo, não será jamais a memória nem a anamnese em sua experiência espontânea, viva e interior. Bem ao contrário: o arquivo tem lugar em lugar da falta originária e estrutural da chamada memória. (DERRIDA, 2001, p. 22).

Memória inconsciente, fundada pela diferença e que pode, enfim, abrir o sujeito para uma impaciência absoluta de um desejo de memória frente àquilo que arruína, desvia ou destrói, àquilo que covardemente se extermina:

Brasil, chegou a vez! De ouvir as Marias, Mahins, Marielles, malês. Brasil, meu nego! Deixa eu te contar. A história que a história não conta. $\mathrm{O}$ avesso do mesmo lugar. Na luta é que a gente se encontra.

Disse o novo hino datado de 2019, portador do discurso que, claramente, contraria o discurso predominante instituído por séculos no imaginário popular. Não mais aquele que tanto reinou nos registros oficiais e que nem acreditava que no Brasil tivesse havido escravidáo, morte, tortura, violências, mas sim o que dá voz ao mal e foi trazido em festa.

Passado o carnaval, ficam as marcas, alguma trilhas. Sustentação dos contrários que marcam os arquivos da história, consideração das ambiguidades como palavras que não permitem o apagamento dos paradoxos inerentes ao arquivo, leitura do arquivo como apagamento e acontecimento a um só tempo, comprometimento com o passado que temos pela frente. Talvez Derrida tenha oferecido alguns bons ingredientes para a construção de narrativas futuras, hinos e cançôes ilustrativas da história brasileira. 


\section{Referências}

BENJAMIN, Walter. Sobre o conceito da história. In: BENJAMIN, Walter. Magia e técnica, arte e politica: ensaios sobre literatura e história da cultura. 8a. ed. revista. Tradução de Sérgio Paulo Rouanet; Márcio Seligmann-Silva (revisão técnica). São Paulo: Brasiliense, 2012.

BIRMAN, Joel. Arquivo e Mal de arquivo: Uma leitura de Derrida sobre Freud. Revista Natureza Humana, v. 10, n. 1, p. 105-128, 2008.

DERRIDA, Jacques. Mal de Arquivo: uma impressão freudiana. Tradução de Claudia de Moraes Rego. Rio de Janeiro: Relume Dumará, 2001.

DUQUE-ESTRADA, P. C. Jamais se renuncia ao Arquivo - Notas sobre o "Mal de Arquivo" de Jacques Derrida. Revista Natureza Humana, v. 12, n. 2, p. 1-16, 2010.

ENDO, Paulo. O que a esquerda teria a aprender com a recusa de Jean Wylys e o carnaval brasileiro de 2019. Disponível em: https://psicanalisedemocracia.com. br/2019/03/o-que-a-esquerda-teria-a-aprender-com-a-recusa-de-jean-wyllys-e-ocarnaval-brasileiro-de-2019-por-paulo-endo/. Acesso em: 20 fev. 2020.

FREUD, Sigmund. A Nota sobre o "Bloco Mágico". In: FREUD, Sigmund. O Eu e o Id, "Autobiografia" e outros textos (1923-1925). Obras Completas. Vol. 16. Tradução de Paulo César de Souza. São Paulo: Companhia das Letras, 2010 [1925].

FREUD, Sigmund. Carta 52. In: FREUD, Sigmund. Publicaçōes Pré-psicanaliticas e Esboços Inéditos (1886-1889). Vol. I. Ed. Standard Brasileira das Obras Psicológicas Completas. Tradução de Jayme Salomão. Rio de Janeiro: Imago, 1996 [1869].

FREUD, Sigmund. O Mal-Estar na Cultura . Tradução de Renato Zwick. Sáo Paulo: L\&PM, 2015 [1930].

FREUD, Sigmund. Sobre o fetichismo. In: FREUD, Sigmund. Inibição, sintoma e angústia, o futuro de uma ilusão e outros textos (1926-1929). Obras Completas. v. 17. Tradução de Paulo César de Souza. São Paulo: Companhia das Letras, 2010 [1927].

GUELLER, Adella Stoppel. Vestígios do tempo. Paradoxos da atemporalidade no pensamento freudiano. Sáo Paulo: Arte e Ciência, 2005.

MANNONI, O. (1973). Eu sei, mas mesmo assim. In: Chaves para o imaginário. Tradução de Lígia Maria Pondé Vassalo. Rio de Janeiro: Vozes.

MATOS, Olgária. TVCult investiga Jacques Derrida. 2004. (11m19s). Disponível em: <https://www.youtube.com/watch?v=JstTXJMbb-0>. Acesso em: 08 jul. 2018. 
RODRIGUES, Carla. Jacques Derrida: pensar a desconstrução. Revista Brasileira de Literatura Comparada. n. 9, p. 330-335, 2006.

SELIGMANN-SILVA, Márcio. Desloucamentos: língua errante/apátrida. Percurso Revista de Psicanálise, São Paulo, p. 59-68, 2018.

TORRES FREIRE, V. O intelectual da discordância. Folha de São Paulo, São Paulo, 3 dez. 1995. Disponível em: <https:/www1.folha.uol.com.br/fsp/1995/12/03/ mais!/4.html>. Acesso em: 08 jul. 2018.

VERÍSSIMO, Tânia Corghi. O racismo nosso de cada dia e a incidência da recusa no laço social. Percurso Revista de Psicanálise, São Paulo, 2015.

ZALTMAN, Nathalie. Homo Sacer: o homem matável. In:Percurso Revista de Psicanálise, São Paulo, 2018, p. 11-20.

Tânia Corghi Veríssimo. Pesquisadora do Instituto de Estudos Avançados (IEA) da Universidade de Sáo Paulo (membro do Grupo de Pesquisa Direitos Humanos, Democracia, Política e Memória). Possui Graduação em Psicologia pela PUC-SP. É psicanalista pelo Departamento de Psicanálise do Instituto Sedes Sapientiae (2014), onde realizou especialização em Psicopatologia Psicanalítica Contemporânea e continua vinculada, participando do grupo de pesquisa "A cor do mal-estar" dedicado a pensar o tema do racismo no Brasil. Possui mestrado pelo Programa de Pós-Graduação em Psicologia Escolar e do Desenvolvimento Humano da Universidade de São Paulo. Bolsista do CNPq (2017-2019).

E-mail: tan.verissimo@gmail.com 